\title{
En torno a una enconada rivalidad por el Maestrazgo de Calatrava durante el siglo XV
}

\author{
EMILIO CABRERA *
}

\section{INTRODUCCIÓN}

Durante la Baja Edad Media y muy singularmente en el siglo $x \mathrm{~V}$, la historia de las órdenes militares estuvo llena de querellas y problemas internos, a menudo mal conocidos y estudiados. Entre ellos, el tema de las rivalidades por el acceso a la dignidad maestral es, quizá, uno de los más frecuentemente aludidos, aunque no abunden los estudios referentes a una circunstancia que, como ésa, produjo enormes tensiones, a menudo con repercusión inmediata a nivel de reino, dada la preeminencia de las personas implicadas. No es preciso insistir, por lo tanto, en la importancia del tema ni es necesario tampoco hacer un balance de las situaciones conflictivas que afectaron a las principales cofradias militares del reino de Castilla durante el último siglo de la Edad Media. Baste recordar, sin ánimo de resultar exhaustivos, que la de Alcántara conoció un estado de casi perenne disensión desde que, tras la muerte, en 1453, de Gutierre de Sotomayor, y luego de unos años de interregno, se produjo el acceso al mestrazgo de Gómez Solís de Cáceres, contra el que se alzó el clavero de la Orden Alfonso de Monroy, a partir de 1464. Frente a Monroy, tanto Gómez Solís, como, más adelante, Francisco Solís, debieron de hacer frente a un peligroso rival que no dudaría, años

\footnotetext{
* Universidad de Córdoba.
} 
más tarde, en oponerse también, y por las mismas razones, a la familia Stúñiga, empeñada, por su parte, en lograr la dignidad maestral de Alcántara para uno de los hijos del segundo matrimonio del Conde de Plasencia. El enfrentamiento entre ambos fue uno de los episodios más sonados de la Guerra de Sucesión, pues no en vano Extremadura, que le sirvió de escenario, era teatro obligado de las operaciones militares de aquel a quien la cancillería de Fernando e Isabel denominaban «el aduersario de Portugal» ${ }^{1}$.

La Orden de Santiago conoció parecidas rivalidades. Tras la muerte del Infante don Enrique de Aragón, don Alvaro de Luna ocupó el cargo de maestre que durante tantos años había ostentado su enemigo, aunque tuvo que reducir por la fuerza a Rodrigo Manrique, el cual hizo valer entonces, por primera vez, sus aspiraciones al cargo ${ }^{2}$. El príncipe don Alfonso sucedió a don Alvaro ç) Luna, teóricamente al menos, cuando sólo contaba un año de edad, circunstancia que tal vez revele no sólo la intención de Juan II de dotar espléndidamente al único hijo varón de su segundo matrimonio, sino también con toda probabilidad, su deseo de evitar por ese procedimiento las rivalidades que en el seno de la nobleza podía ocasionar el deseo de conseguir tan sustanciosa presa ${ }^{3}$. Sin embargo, Enrique IV no respetó en todos sus términos la última voluntad de su padre, pues dispuso de las rentas del maestrazgo, e incluso confirió esta últıma dignidad, en 1464, a Beltrán de la Cueva ${ }^{4}$, el cual no pudo conservarla más que unos meses, a causa de la oposición de Juan Pacheco, tutor del joven príncipe -es entonces cuando se aplica por vez primera ese título a don Alfonso ${ }^{5}$-, que no cejó hasta ver el cargo en manos de su protegido, y luego, a su muerte, en las suyas propias. Villena lo ejerció hasta su propia muerte, en 1474, y al producirse ésta se lo disputaron Diego López Pacheco, hijo del fallecido, y otros muchos personajes de la nobleza, entre ellos el Marqués de Santillana y el Duque de Medina-Sidonia ${ }^{6}$, aunque la mayor rivalidad se dio, como es bien

Sobre algunos episodios de la guerra civil en Extremadura, vid. E. CABRERA: «Beatriz Pacheco y los orígenes del condado de Medellín", Anuario de Estudios Medievales, 15, 1985, págs. 513-551.

2 Halconero: Crónica, ed. Carriazo, pág. 479 y siguientes.

3 La voluntad de Juan II fue expresada en su testamento, publicado en Memorias de Enrique IV de Castilla, t. II, Madrid 1835-1913, págs. 111-125.

4 A. Rodriguez VILLA: Bosquejo biográfico de don Beltrán de la Cueva, primer Duque de Alburquerque. Madrid 1981, pág. 148 y siguientes.

5 T. AzCONA: Isabel la Católica, pág. 86.

6 Valera: Memoria de Diversas hazañas, ed. Carriazo, pág. 280. Enríquez: Crónica de Enrique $N$, ed. BAE, pág. 221. 
notorio, entre Rodrigo Manrique y Alfonso de Cárdenas. Uno y otro ejercieron, respectivamente, durante cierto tiempo, la administración de la provincia castellana y leonesa de la Orden y concibieron esperanzas que, siendo más antiguas las del primero, sólo el segundo de ellos logró ver satisfechas ${ }^{7}$.

Por su parte, la Orden de Calatrava conoció situaciones semejantes que resultaría prolijo enumerar aquí. Por ello vamos a referirnos en las páginas que siguen a una serie de episodios, mal conocidos hasta ahora, que enfrentaron, durante dos generaciones, a la familia Girón con la familia Guzmán y que tuvieron como epílogo la trágica muerte de uno de los miembros de este último linaje en la famosa y problemática revuelta de Fuenteovejuna de $1476^{\circ}$. Se trata, en realidad, de una historia o, mejor, de dos historias cuyos protagonistas, Juan Ramírez de Guzmán y Fernán Gómez de Guzmán -padre de hijo, que se sucedieron en la encomienda mayor de Calatrava durante los decenios centrales del siglo $\mathrm{XV}$ - aspiraron a la más amplia dignidad de la Orden. La suerte no les favoreció en su empeño, pero su decidido propósito de lograr el cargo puede contribuir a explicar no sólo la rivalidad que separó, en el seno de la Orden de Calatrava, a la familia Girón de la familia Guzmán, desde 1445 a 1476, sino también algunos de los conflictos surgidos en el seno de la Orden sobre los cuales pueden arrojar mucha luz.

\section{JUAN RAMÍREZ DE GUZMÁN, FERNANDO DE PADILLA Y ALFONSO DE ARAGÓN. TRES CANDIDATOS AL MAESTRAZGO DE LA ORDEN DE CALATRAVA}

Desde la segunda mitad del siglo XIV, la familia Guzmán había ejercido un importante papel en la Orden de Calatrava. Uno de los miembros de esa familia, Gonzalo Núñez de Guzmán, ocupó el cargo de Maestre desde 1384 a 1404. Con su larga etapa de mandato en la Orden y también con la persistente influencia ejercida en el seno de ella por los

\footnotetext{
7 Pulgar: Crónica de los Reyes Católicos, ed. BAE, pág. 249 y siguientes y 257 y siguientes.

8 Sobre el tema de la revuelta de Fuenteovejuna, vid. E. CABRERA: «La sublevación de Fuenteovejuna de 1476: revisión del problema", en Andalucía Medieval: nuevos estudios. Córdoba 1979, págs. 147-174.
} 
de su linaje está relacionado, sin duda, el acceso a importantes cargos de la misma de dos sobrinos suyos, Luis de Guzmán y Juan Ramírez de Guzmán ${ }^{9}$. Es bien sabido hasta qué punto fue importante la fórmula del nepotismo en la provisión de los distintos cargos de las órdenes militares ${ }^{10}$. El primero de los citados sucedió a su tío en el cargo de maestre, tras la corta etapa en que dicho cargo fue ocupado por don Enrique de Villena; Juan Ramirez de Guzmán fue, por su parte, Comendador mayor, y como tal figura ya al menos desde $1429^{11}$. Su larga permanencia en este puesto, unida a su indudable prestigio militar ${ }^{12}$ y la relativa frecuencia con que los titulares del mismo lograban alcanzar la máxima dignidad de la Orden hizo que Juan Ramírez de Guzmán concibiera esperanzas en tal sentido cuando, en 1443, se le agravó al Maestre Luis de Guzmán la enfermedad que poco después le llevaría a la tumba ${ }^{13}$. Pero, a causa de un malentendido - a través del cual se propagó por la Corte la falsa noticia de que el Maestre había fallecido cuando, en realidad, estaba tan sólo muy enfermo- Juan Ramírez de

9 Al último de ellos se le conoce habitualmente como Carne de Cabra. F. PEREZ DE GuZMÁN: Generaciones y semblanzas. ed. BAE, vol. LXVIII, pág. 704 B. En una escritura del año 1393 recogida por Salazar aparecen, como otorgantes de la misma, junto al maestre Gonzalo Núñez de Guzmán, otros dos miembros de su familia: Frey Juan de Guzmán, comendador de Collado, y Frey Juan Ramírez de Guzmán, comendador de Otos. No es posible asegurar o negar que este último personaje sea exactamente el mismo que, con idéntico nombre, llegaría a ser comendador mayor unos decenios más tarde. Vid. Colección Salazar, M-130, fols. 45-47, doc. de 1393, diciembre, 1 Almagro. Juan Ramírez de Guzmán vuelve a aparecer, también como comendador de Otos en otra escritura de 1399 (Ibidem, M-130, fols. 52v-56v, doc. de 1399, julio, 23. Toledo).

10 A través de la composición del Capítulo General de la Orden de Alcántara durante el maestrazgo de Gutierre de Sotomayor (1432-1453) comprobamos que una buena porción de los componentes de ese órgano de gobierno - siete, en total- estaban en manos de miembros de su familia, pertenecientes a los linajes Sotomayor, Raudona, Monroy o Topete. AHN, Osuna, Leg. 323-41, con referencia al capítulo general celebrado los días 13 y 14 de mayo de 1448.

${ }_{11}$ Crónica de Juan II, ed. BAE, pág. 467 A. Respecto al año 1430, pág. 489 B. Se le cita también, al año siguiente, Ibidem, 495 A. Vid. también Crónica de don Alvaro de Luna, Madrid, Espasa, 1940, pág. 102. Por esos años, otro miembro de la familia, Diego Ramírez de Guzmán, era comendador de Zorita. Vid. Colección Salazar, M-8, fols. 274-278, doc. de 1431, mayo 31, s.l.

${ }_{12}$ Pulgar, en sus Claros varones subrayó los méritos militares de Juan Ramírez de Guzmán, a quien compara con los grandes caudillos de la Antigüedad. « ¿Cual de los capitanes romanos - dice Pulgar-pudo pujar al esfuerço de don Juan Ramires, comendador mayor de Calatrava, de linaje noble de Guzmán; el cual mostrava tan grand ardideza en las batallas, e tenía tanta destreza en el governar las armas, que el braço desnudo, el espada en la mano, esforçando a los suyos, firiendo a los enemigos, venció muchas batallas de moros; e con tanto esfuerço acometía, e con tal perseverancia durava en los peligros, que comoageno de todo miedo lo imprimía en los enemigos?». Hernando del PulGar: Claros varones de Castilla, ed. Espasa Calpe, Col. Austral n. ${ }^{\circ} 832$, págs. 90-91.

13 Crónica Juan II, ed. BAE, pág. 609 B. 
Guzmán se precipitó, sin duda, a causa de su ambición por ocupar el puesto de su pariente ${ }^{14}$. Fernando de Padilla, el clavero, que, aspirando también al cargo, gobernaba la Orden en nombre del maestre enfermo, no dudó en hacer frente al comendador mayor y a sus partidarios. Por esa época, Juan Ramírez de Guzmán era muy afecto al infante don Enrique de Aragón, del cual solicitó ayuda militar para ocupar las tierras del Maestrazgo, confiando en que no dejaría de obtener los votos de los comendadores, necesarios para conseguir la dignidad de Maestre ${ }^{15}$. En efecto, el Infante le proporcionó 100 jinetes y 200 hombres de $\operatorname{armas}^{16}$. Pero no fueron suficientes para imponerse al clavero que, con un contingente de tropas algo superior, derrotó a su adversario en Barajas, cerca de Daimiel ${ }^{17}$. El propio comendador mayor, un hijo suyo y dos de sus hermanos fueron hechos prisioneros mientras que otros parientes murieron en el combate ${ }^{18}$. $\mathrm{Y}$ aunque Juan II intervino de inmediato para conseguir la libertad del comendador mayor y de sus parientes, Fernando de Padilla retuvo a los prisioneros alegando ser competencia del Maestre de la Orden y, en última instancia, del Papa, la resolución del conflicto ${ }^{19}$. Pocos días después fallecía Luis de Guzmán (24 de febrero de 1443), el cual fue sepultado en el Sacro Convento ${ }^{20}$.

14 Parece que no hay dudas sobre la relación exacta de parentesco entre el maestre y el comendador mayor. Fernán Pérez de Guzmán que, como miembro del linaje, debía conocerles muy bien, se limita a decir en sus Generaciones y semblanzas (Ed. BAE, pág. 704 B) que ambos eran sobrinos de Gonzalo Núñez de Guzmán, de lo cual parece deducirse que ambos eran primos. Por su parte, F. RAdes y Andrada, en su Chrónica..., fol. 70 $r .{ }^{\circ} \mathrm{B}$ y $70 \mathrm{v} .^{\circ} \mathrm{A}$, afirma que eran primos.

15 Crónica de Juan II, pág. 609. Rades, ob. cit. fols. 69 v. ${ }^{\circ}$ y 70 r..

16 «E como don Juan Ramírez de Guzmán fuese mucho del Infante don Enrique, demandóle ayuda de gente para ocupar las tierras del Maestrazgo, teniendo que habiendo los lugares e los votos de los comendadores de Calatrava habría el Maesrazgo". Crónica de Juan II, pág. 609.

17 Ibidem.

18 Ibidem. Según Rades, el hijo del Comendador mayor se llamaba Juan y sus hermanos Ramiro y Fernando. No nos consta la presencia en ese episodio del otro hijo, el futuro comendador mayor, Fernán Gómez de Guzmán, quien con el nombre de Fenando de Guzmán y con el título de comendador de Talavera (de los bienes que la Orden tenía en Talavera, se entiende) y de las casas de Plasencia, se halla perfectamente documentado poco tiempo después. Cfr. Rades: Crónica..., fols., $78 \mathrm{r.}{ }^{\circ}$, en relación con la reunión del Capítulo general celebrado en Almagro el 19 de septiembre de 1445 en el cual salió elegido maestre Pedro Girón.

19 Crónica de Juan /I, pág. 610 B. Rades, por su parte, afirma que el Maestre no sólo a causa de la gravedad de su dolencia, sino, sobre todo, enojado con su primo el comendador mayor, no quiso atender al doctor García López de Carvajal, que, como enviado del Rey, se había dirigido a Almagro para interceder por los prisioneros. RADEs, ob. cit., fols. $69 \mathrm{v}^{\circ}, 70 \mathrm{r} .{ }^{\circ}$.

20 Ibidem. O'Callaghan afirma que la muerte de Luis de Guzmán se produjo el 24 de febrero de 1443. Vid. O'CALLAGHAN: "Don Pedro Girón, master of the Order of Calatrava" 
La muerte del maestre puso de manifiesto en seguida las intrigas que durante meses habian debido de tejerse en torno a su sucesión. Rades afirma que el clavero, sin comunicar la noticia al Rey, se hizo elegir como maestre inmediatamente después ${ }^{21}$. La notificación le fue hecha a Juan II a través de una carta fechada el 3 de marzo ${ }^{22}$. Por su parte, Juan de Navarra, que deseaba el cargo para su hijo bastardo Alfonso de Aragón, había hecho ya, tiempo atrás, las gestiones necesarias cerca del Papa a fin de obtener la imprescindible dispensa, dada la escasa edad -14 años- de su hijo y su condición de ilegítimo ${ }^{23}$. $Y$, por su parte, el comendador mayor, aunque no estaba en muy buena situación, pues se hallaba aún preso y en poder de Fernando de Padilla, sólo provisionalmente y para obtener su libertad renunció a sus aspiraciones. Esto último fue lo que le exigió el maestre electo para liberarle ${ }^{24}$. Juan II, que apoyaba la candidatura de Alfonso de Aragón y había instado a los comendadores de la Orden a que designasen a este último, se vio obligado a consentir que los Infantes don Juan y don Enrique trataran de imponer a su candidato por la fuerza. En efecto, un ejército coducido por el infante don Enrique sitio al maestre electo, que se había encastiliado en Calatrava la Nueva. Actuaba también a favor del rey de Navarra Rodrigo Manrique, mientras Juan de Guzmán (un hijo del maestre fallecido) apoyaba al electo y causaba, al mismo tiempo, grandes disturbios en Andalucía ${ }^{25}$. La crisis interna de la Orden de Calatrava acentuó las divisiones existentes tanto en el seno de la nobleza como en el de la misma Corte, pues el príncipe don Enrique, y también el almirante y los condes de Haro y de Alba, apoyaban al maestre electo ${ }^{26}$. Por su parte, el tercer candidato en discordia, Juan Ramírez de Guzmán, sin abandonar, en su fuero interno, sus aspiraciones al maestrazgo de Calatrava, entendió que la mejor opción era la de apoyar la candidatura

Hispania, XXI, 1961, pág. 8, con ref. a AHN, Documentos eclesiásticos de Calatrava, núm. 128 , fol. 3 V. ${ }^{\circ}$.

21 RADES, ob. cit., fol. $71 \mathrm{r}^{\circ}$.

22 Archivo Ducal de Frías, Caja $6, n .^{\circ} 5$.

23 O'Callaghan, ob. cit. pág. 8.

${ }^{24}$ Crónica de Juan II, pág. 612 . En ella se afirma que Juan II, utilizando como mediador a Pedro López Padilla, padre del maestre electo, consiguió la libertad del comendador mayor y de su familia, pero este último tuvo que aprobar la elección realizada «e le besó la mano por Maestre, e le hizo aquellos juramentos y omenages e solemnidades que segùn los estatutos de la Orden de Calatrava se requieren hacer en tal caso".

$25 \mathrm{Ibidem}$. Un documento redactado el 21 de marzo recoge la instancia de los comendadores de Calatrava al hijo del maestre muerto, Luis de Guzmán, para que defendiera las tierras del maestrazgo frente a Rodrígo Manrique. Vid. Archivo Ducal de Frías, Caja 6 n. ${ }^{\circ}$ 6 , doc. de 1443, marzo, 21.

26 ibidem. 
aragonesa, faltando así al juramento que había hecho poco tiempo antes a Fernando de Padilla, el cual alegaba el comendador mayor haberlo prestado en situación de privación de libertad y para obtenerla por ese medio $^{27}$.

La inesperada muerte de Padilla, el maestre electo, el 22 de junio de 1443, a consecuencia de un accidente, durante el cerco de Calatrava, lejos de contribuir a solucionar el problema, terminó por agravarlo, a la larga ${ }^{28}$. Juan de Guzmán, el hijo del anterior maestre, temiendo perder algunas de las perrogativas o, incluso de los bienes más o menos legitimamente heredados de su padre continuó siendo una fuente de disturbios durante bastante tiempo ${ }^{29}$. Sin embargo, el gran problema fue que la desaparición del clavero reavivaba las aspiraciones de Juan Ramírez de Guzmán al maestrazgo de Calatrava, sobre todo cuando, un mes más tarde, el rey de Navarra dio el llamado “Golpe de Estado de Rámaga" (9 de julio de 1443) que tuvo como efecto la prisión de Juan II y ahondó más aún las diferencias entre los miembros de la nobleza. Consecuencia de todo ello fue el reforzamiento del partido de don Alvaro de Luna simplemente como reacción contra la prepotencia del rey de Navarra; y es, seguramente, en ese contexto donde hay que situar las nuevas aspiraciones de Juan Ramírez de Guzmán al maestrazgo de Calatrava. En efecto, dadas las expectativas que la nueva situación ofrecía, el comendador

${ }^{27}$ Ibidem. Vid. también RADES, ob. cit., fol. 71 r. ${ }^{\circ}$. La Crónica de Juan II nos dice que el comendador mayor mantuvo, incluso, una larga entrevista con varios miembros de la familia del clavero, pero no pudo llegar a ningún acuerdo con ellos. No sabemos cual era el propósito de esas conversaciones, aunque parece deducirse del contexto que, en ese momento, Juan Ramírez de Guzmán apoyaba, más o menos de buena gana, la candidatura de Alfonso de Aragón. Crónica de Juan II, pág. 612.

${ }_{28}$ El maestre electo murió a consechencia de un golpe en la cabeza que se produjo al disparar una catapulta contra los componentes del ejército sitiador. Crónica de Juan II, pág. 612 y RADES, ob. cit., fol $71 r^{\circ}$. O'CALLAGHAN, ob. cit. pág. 10, fecha la muerte de Fernando de Padilla el día citado, tres meses después de su elección como maestre. Véase también sobre el tema, la descripción, un tanto críptica y desordenada que hace $A$. DE Palencia: Crónica de Enrique IV, ed. BAE, vol. I, pág. 30.

29 Todavía en septiembre de 1444 , el príncipe don Enrique garantizaba a Juan de Guzmán que no le quitarian los bienes que había recibido de su padre. (Archivo Ducal de Frías, Caja 6 n. ${ }^{\circ}$, doc. de 1444, septiembre, 30). Todo ello dio lugar a un conflicto aún sin resolver cuando Pedro Girón accedió al maestrazgo (Ibidem, Caja 1 n. ${ }^{\circ}$ 26). Juan de Guzmán reclamaba también ciertas cantidades que habia gastado en defensa de las tierras de la Orden a raíz de la muerte de su padre (Ibidem, Caja 6 n. ${ }^{\circ}$, doc. de 1447, febrero, 13. Valladolid). La confirmación que Juan II hizo en 20 de abril de 1447 de una aprobación otorgada por él mismo, cinco años antes, del testamento del maestre de Calatrava (Ibidem, Caja 31 n. 6) muestra que, todavía en esa fecha, seguía en pie el problema de Juan de Guzmán. 
mayor rompió su antigua amistad con los Infantes de Aragón y se sumó, al parecer, de manera tan decidida y sincera a la facción contraria, que su ruptura hace pensar no sólo en una maniobra oportunista, sino quizá también en una decisión movida, en parte, por el despecho hacia sus antiguos aliados. En todo caso, la defección del comendador mayor de Calatrava resultó tan llamativa en la época que incluso fue recogida en algún cancionero ${ }^{30}$.

La expedición del infante don Enrique a Andalucía, efectuada en los últimos meses de 1443 y primeros de 1444, dio a Juan Ramírez de Guzmán la ocasión de hacer méritos para la obtención del maestrazgo de Calatrava, el cual estaba ahora en manos de su hijo bastardo de quien, contra toda justificación, tenía prisionero al rey de Castilla. En la documentación referente a las operaciones militares en torno a la defensa de Sevilla y la liberación de Carmona, Alcalá de Guadaira y Córdoba, sometidas al infante don Enrique, Juan Ramírez de Guzmán figura siempre como maestre de Calatrava - título que él se daba a sí mismo por esos meses- si bien su papel en esa campaña aparece un tanto desdibujado y en segundo plano respecto del maestre de Alcántara, que fue quien acaudilló la expedición castellano-portuguesa con la que se puso fin a la "aventura andaluza» del Infante don Enrique de Aragón. ${ }^{31}$

\section{JUAN RAMÍREZ DE GUZMÁN FRENTE A PEDRO GIRÓN}

A lo largo de la primera mitad del año 1444 quedó neutralizada la amenaza de los Infantes de Aragón en Andalucía y seriamente comprometida su influencia en el resto del reino, del cual huyó el rey de Navarra

30 Así lo hace, por ejemplo, las Coplas de Ay Panadera, en las cuales se glosa la participación de Juan Ramírez de Guzmán en la batalla de Olmedo donde actuó en el ejército que hizo frente a los Infantes de Àragón. La estrofa XXXV no puede resultar más significativa: Viniendo de la frontera/ el mayor Comendador,/ desemparó (a) su señor,/ de quien gran bien recibiera,/ e como quien desespera' de toda gran nombradia, 1 más vergüenza no teníal que una puta carcaveral ¡Dí panadera! ARTiGas: “Nueva redacción de la Coplas de Ay Panadera según un manuscrito de la Biblioteca de Menéndez Pelayo", en Estudios «In Memoriam" de A. Bonilla y San Martín, 1, Madrid 1927, págs. 75-89.

31 Cfr. E. Cabrera: El condado de Belalcázar (1444-1518), págs. 114 y siguientes y E. Benito Ruano: "La expedición portuguesa de 1444 en socorro de Sevilla". Actas das II Jornadas Luso-Espanholas de História Medieval, I, Oporto 1987, págs. 333-355. 
acompañado por su hijo, el maestre de Calatrava. Aunque éste siguió usando ese título, la situación parecía óptima para la expectativas del comendador mayor porque en los conflictos que siguieron Alfonso de Aragón apoyó a su padre, el rey de Navarra, y no a su rey, que era el de Castilla, con lo cual justificaba plenamente el que Juan II y el partido del condestable, revisasen su elección en el momento más oportuno ${ }^{32}$. $Y$ ese momento llegó tras la derrota de los infantes en Olmedo (1445). Juan Ramírez de Guzmán, en su intento de hacer méritos ante el rey y el partido del condestable participó de manera activa en la batalla ${ }^{33}$. Y cuando ésta terminó, con la derrota de los Infantes, pudo albergar la esperanza de que en el reparto de los despojos de los vencidos, que poco después se efectuó, lograría, por fin, el maestrazgo. Fue una frustración más, pues no había contado con el proyecto que entre tanto había ido madurando Juan Pacheco, el cual deseaba ese puesto para su hermano, el doncel del rey, Pedro Girón. Lo más doloroso para Ramírez de Guzmán no fue, tal vez, con ser mucho, el hecho de verse obligado a renunciar al maestrazgo; es que, según parece, su decidida actuación militar contraria al partido de los Infantes de Aragón, tanto en la campaña de 1444 en Andalucía como en la batalla de Olmedo, no fue lo bastante estimada como para merecer recompensa alguna. $Y$ esa real $O$ aparente injusticia añadida, a la amargura de la renuncia -era ya la segunda oportunidad perdida - el despecho de quien, habiendo abandonado una opción en la que estuvo militando durante mucho tiempo, se había puesto luego al servicio de la causa del condestable seguramente con toda la entrega y el valor que, según parece, eran las notas más conocidas de su carácter ${ }^{34}$. Cuando, al hacer el reparto de despojos de los vencidos, se procedió a adjudicar nuevamente los maestrazgo de Santiago y de Calatrava en las personas de Alvaro de Luna y Pedro Girón, respectivamente, hubo dos resentidos: Rodrigo Manrique, comendador de Segura de la Sierra, y el propio Juan Fiamírez de Guzmán ${ }^{35}$. A ellos hay que

32 RADES, ob. cit., fols. 71 v. ${ }^{\circ}$ y 72 r. $^{\circ}$ A.

${ }^{33}$ Crónica de Juan II, pág. 628 B. Crónica de don Alvaro de Luna, ed. Carriazo, pág. 167.

${ }_{34}$ Vid. textimonio ya citado en Pulgar: Claros varones de Castilla, págs. 90-91.

35 F. Pérez de Guzmán califica la elección de maestre de don Alvaro de Luna de no haberse hecho "según Dios y orden». Y al glosar la elección de Pedro Girón para la de Calatrava nos informa de que Juan II permitió la promoción de este último maestrazgo "por complacer al Príncipe su hijo, como por le atraer a su opinión contra el Rey de Navarra, $(y)$ mandó que se juntasen los comendadores de Calatrava y eligiesen a este Pero Girón en lugar de don Alfonso, hijo del Rey de Navarra; lo qual los Comendadores luego hicieron, aunque en esta elección no quiso ser don Juan Ramirez de Guzmán, Comendador mayor de Calatrava; pero todavía Pero Girón fue elegido maestre, e con el favor quel Rey le dió 
añadir un tercero, el obispo Barrientos, respecto del cual la ingratitud del rey resulta difícilmente comprensible ${ }^{36}$.

Rades afirma que en el seno de la Orden de Calatrava se produjo un cisma al mantener sus aspiraciones al maestrazgo tanto Pedro Girón como el candidato aragonés y el comendador mayor ${ }^{37}$. Alfonso de Aragón, con su sede en Alcañiz, siguió titulándose maestre hasta $1455^{38}$. Rades presenta en su crónica una situación muy tensa entre el comendador mayor y el nuevo maestre tras la elección ${ }^{39}$. Según el historiador de las órdenes militares, Juan $I I$ y el Príncipe don Enrique trataron de evitar un enfrentamiento armado entre los dos sectores de la Orden de Calatrava intentando llevar a ambos contendientes a un acuerdo. Parece que, al margen de las alianzas que uno y otro pudieran conseguir, el maestre tenía la parte principal de su fuerza en el Campo de Calatrava, mientras que el comendador mayor tenía la suya en Andalucía, con sus puntos fuertes en Osuna, sede de la encomienda mayor, Martos y otras plazas. La información que proporciona Rades hace suponer que éstas no eran escasas y que incluso las poseía en el Campo de Calatrava ${ }^{40}$. Tenía también en su poder la plaza de Zorita ${ }^{41}$. Por eso, las cláusulas

muy prestamente cobró las más fortalezas del Maestrazgo de Calatrava, como quiera que esto fue contra toda justicia". Crónica de Juan II, págs. 635 B y 636 A. Por su parte, Palencia (en un pasaje donde mezcla acontecimientos sin una secuencia cronológica precisa) se expresa en parecidos términos al decir que «El consentimiento de este privado (don Juan Pacheco, en relación con la nueva boda de Juan II) se obtuvo mediante la concesión de los considerables Estados del marquesado de Villena para él, y la gran dignidad del maestrazgo de Calatrava para Pedro Girón, su hermano, a pesar de la legítima elección del muy ilustre y esforzado don Juan Ramírez de Guzmán, con menosprecio del mérito de tal caudillo, y en mengua del honor del noble don Fernando de Padilla, clavero de la Orden, elegido Maestre por algunos comendadores". PALENCIA: Crónica de Enrique $I V$, ed. BAE, vol. I, págs. 30-31. Rades y Andarada nos proporciona la lista de comendadores de la orden que votaron a uno y otro candidato. Pedro Girón obtuvo votos de veintidós comendadores, mientras que Juan Ramírez de Guzmán consiguió tan sólo los de seis: Frey Fernando de Guzmán, su hijo, comendador de Talavera y de las Casas de Plasencia; Frey García López de Sosa, comendador de Aceca, Frey Gómez de Palomares, comendador del Collado, que luego lo fue de Caracuel, y Frey Juan Morán, Frey Perafán de Ribera y Frey Juan de Figueroa, caballeros de la Orden sin encomiendas. Vid. RADES, ob. cit. fol. $78 \mathrm{r}$. . En otro lugar de su obra, Rades contabiliza en favor de Juan Ramírez de Guzmán los votos de tres comendadores, cuatro caballeros y catorce clérigos. Ibidem, fol. $73 \mathrm{r} .^{\circ}$ O'CALLAGHAN, ob. cit. nota 58 , nombra varios miembros de la orden que prestaron acatamiento a Girón, aunque no figuran en la lista de los que, según Rades, le dieron su voto.

36 HaLCONERO, Cap. CCCXLVII.

${ }^{37}$ Rades, ob. cit., fol. 72 r. ${ }^{\circ}$.

38 Ibidem.

39 Ibidem, fol. 72 v.

40 Ibidem.

${ }^{41}$ Ibidem. Vid. también Crónica de Juan II, cap. XXVI. 
del acuerdo propuesto para la pacificación de la Orden, junto a ciertas concesiones aparentemente generosas, podían parecer en algunos aspectos demasiado drásticas para un comendador mayor que era consciente de su fuerza. Entre ellas se especificaba, en primer lugar, la renuncia al título de maestre por parte de Juan Ramírez de Guzmán; la exigencia de que acatase a Girón en acto solemne y en el Sacro Convento; la entrega de cuantas fortalezas y encomiendas tuviera en su poder, excepto las de la encomienda mayor y las encomiendas de sus propios hijos ${ }^{42}$. Se le garantizaba, en cambio, la conservación de su cargo y, así mismo, el perdón para aquellos que se sumaron a su causa. Finalmente, Juan Ramírez de Guzmán recibiría en compensación 50.000 maravedies de juro anual con cargo a la Mesa maestral y 150.000 más que le prometía el rey con cargo a la Hacienda real; además de eso, Juan II prometía al comendador mayor hacerle una merced de 300 vasallos situados en Atienza, utilizando a ese fin uno de los despojos de Juan de Navarra, al que había pertenecido esa plaza ${ }^{43}$.

Todo ello sucedía en septiembre de $1445^{44}$. Pero las fuertes tensiones que se produjeron entre el Rey y el Príncipe de Asturias inmediatamente después dejaron el acuerdo en suspenso. En los preparativos militares que se hicieron para un posible enfrentamiendo armado, el heredero de la Corona contó con la colaboración de Pacheco y de su hermano, el maestre de Calatrava, y la nueva división del reino que tal actitud traía consigo pudo alimentar nuevamente las aspiraciones de Juan Ramírez de Guzmán. La concordia de Astudillo (14 de mayo de 1446), que aplaco, de momento, los ánimos, intentó nuevamente encontrar una solución al problema de Rodrigo Manrique, en la Orden de Santiago, y de Juan Ramírez de Guzmán, en la de Calatrava. Como tal, la solución figura en una de las cláusulas de dicha concordia: Juan Ramírez de Guzmán era compensado, por la renuncia al maestrazgo, con 300 vasallos y una renta de 300.000 maravedíes $^{45}$. Sin embargo, el acuerdo defi-

42 Las encomiendas que Rades cita como integrantes de la Ericomienda mayor y las que tenían los hijos de Juan Ramírez de Guzmán eran: Osuna, Agudo, Abenójar, Mestanza, Caracuel, Otos y Guadalerza, de lo cual se deduce fácilmente que la fuerza de comendador mayor era considerable, incluso en el Campo de Calatrava. RADES, ob. cit. fol. $72 \mathrm{v}$.

43 RADES, ob. cit., fol. 72 v. ${ }^{0}-73$ r. ${ }^{\circ}$.

44 O'Callaghan, ob. cit. pág. 17.

45 Pedro Carrillo de Huete recogió el acuerdo sumariamente en su crónica: «Yten, que el maestradgo de Calatrava quedase con don Pedro Girón, hermano del dicho marqués de Villena, e fuese fecha alguna enmienda de vasalios e dineros al maestre don Juan Ramírez de Guzmán". HalCONERO, pág. 473. La Crónica de Juan II, que incluye el texto, resulta más explícita: ademas de conservar las villas de su Encomienda, se le concedian 300 vasallos 
nitivo parece que no empezaría a lograrse hasta 1448. En junio de ese año, Pedro Girón logró la aprobación de su nombramiento por el Capítulo general de la Orden cisterciense. Contaba, así mismo, con la aprobación del Papa ${ }^{46}$. A finales de ese mes, un preacuerdo establecido en Zorita entre el clavero, como emisario del maestre, y el comendador mayor quedó fijado luego en los últimos días de julio y primeros de agosto siguientes, en los cuales se firmaron, en Segovia y en el monasterio del Paular, las escrituras de concordia entre el maestre y el comendador mayor ${ }^{47}$. Una cédula otorgada el $1 .^{\circ}$ de agosto por el príncipe don Enrique, comprometía a éste en el cumplimiento, por parte de Pedro Girón de los acuerdos adoptados, tema en el cual insistia otra escritura, del mismo día, otorgada po don Juan Pacheco, el hermano del maestre ${ }^{48}$. Los términos eran semejantes a aquellos que, con menos éxito, se habían establecido anteriormente ${ }^{49}$.

\section{FERNÁN GÓMEZ DE GUZMÁN, NUEVO COMENDADOR MAYOR}

No están bien documentados los últimos años de Juan Ramírez de Guzmán al frente de la encomienda mayor de Calatrava. Incluso se desconoce el efecto inmediato que tuvo la solución adoptada en El Paular durante el verano de $1448^{50}$. Se suele conectar la merced de vasallos hecha por Juan II al comendador mayor de Calatrava con la constitución del señorío de Teba ${ }^{51}$. Sin embargo, ese señorío empieza a estar bien

\footnotetext{
y se le asignaba una renta de $300.000 \mathrm{mrs}$. anuales, a pagar, por mitad, con cargo a la Mesa central y a la Hacienda real. Debía devolver todas las plazas que había tomado y acataria como su maestre a Pedro Girón. Crónica de Juan II, pág. 644 B.

4e O'Callaghan, ob. cit., pág. 19.

47 Colección Salazar, D-14, fols. 256-258, doc. de 1448, julio, 30, Segovia y D-14, fols. 253-255, doc. de 1448, agosto, 1.

48 Colección Salazar, D-14 fols. 253 y M-25, fols. 195-196, respectivamente.

49 El rey entregaba a Juan Rodríguez de Guzmán, además de 300 vasallos, un juro de heredad de $50.000 \mathrm{mrs}$. y $100.000 \mathrm{mrs}$. más de por vida. El maestre debía garantizarle otros 150.000 anuales con cargo a la rente de almadenes.

${ }_{50}$ El 28 de septiembre de dicho año, Juan II, desde Burgos, concedía una merced de 300 vasallos a Juan Ramírez de Guzmán, como compensación por su renuncia al maestrazgo y por la entrega de las plazas de la Orden que habia conservado en su poder. Cfr. RAH, Colección Salazar, M-124, fiks, 147-149.

${ }_{51}$ Así lo ha hecho E. SOLANo: La Orden de Calatrava en el siglo xv, pág. 89 y nota n. ${ }^{\circ} 189$.
} 
documentado en la persona de su hijo, Juan de Guzmán. La caprichosa y cambiante onomástica de la época - especialmente dificultosa en la familia de los Guzmán- no permite fijar el tema sin un estudio previo del linaje, que está aún por hacer ${ }^{52}$. Por el contrario, la creación del señorío de Ardales, villa vecina de Teba que el señor de ésta conquistó a los musulmanes y obtuvo, en señorio, en 1465, está mucho más clara ${ }^{53}$. Tampoco se sabe a ciencia cierta cuando murió el comendador mayor Juan Ramírez de Guzmán, aunque consta que en 1453 vivía aún ${ }^{54}$. Su hijo y sucesor en el cargo, Fernán Gómez de Guzmán, ostentaba ya la encomienda mayor pocos años después. Aunque sabemos que ya pertenecía a la orden de Calatrava en 1445, no está del todo claro cómo y cuándo se produjo su acceso a tal cargo, aunque se puede inferir que sucedió en él a su padre en torno a $1455^{55}$.

Sobre la figura de Fernán Gómez de Guzmán parece como si no existiera otra imagen que la que permiten inferir las páginas que dedica el cronista Rades y Andrada a la revuelta de Fuenteovejuna de 1476, en las cuales se basó Lope de Vega para montar el argumento de su famosa obra teatral ${ }^{56}$. De aquéllas $y$, sobre todo, de esta última es fácil obtener una imagen negativa de este famoso y, al mismo tiempo, des-

52 Juan de Guzmán está documentado ya en 1442, como beneficiario de un juro de $20.000 \mathrm{mrs}$. conseguido por intercesión de la reina de Castilla cuando no era, probablemente, más que un niño de corta edad. Colección Salazar, M-25, fol. 165. Se trata, seguramente, del mismo personaje que, en 1456, y con el nombre de Juan Ramírez de Guzmán, otorga arras a doña Juana Ponce de León, su esposa (Ibidem, fols. 192-194) y lleva a cabo importantes misiones durante el reinado de Enrique IV: acción contra Alfaro, en 1459 (Colección Salazar, M-25, fols. 168 r y v); enviado del rey en Zamora, en 1463 (Ibidem, fols. 166v-167); señor de Ardales y miembro del consejo del rey, en 1465 (Ibidem, fols. 168 y $204 \mathrm{v}-206$, respectivamente), para terminar siendo, en el reinado siguiente, corregidor de Segovia en 1476 (Ibidem, fol. 163 v) y mariscal de Castilla, en 1484 (Ibidem, fols. 203 r y v).

53 Colección Salazar, M-25, fols. 168 r y v.

${ }^{54}$ A través de un testimonio existente en el Archivo Ducal de Medinaceli aparece el comendador mayor de Calatrava reconociendo haber recibido de su sobrino, don Pedro de Aguilar, 100 doblas de oro de la banda que le había prestado. ADM, Priego, 38-44(2).

${ }_{55}$ Eso es, al menos, lo que sugiere la dedicatoria que $P$. Tafur le hizo en su libro Andanças e viages, de Pero Tafur. En esa dedicatoria, Fernán Gómez de Guzmán aparece ya citado, con el nombre de Fernando de Guzmán, como comendador mayor de Calatrava. El libro fue compuesto, a juicio de J. Vives - que escribe la introducción histórica de la edición- entre 1454 y 1457 , pues son las fechas respectivas de la muerte de Juan II de Castilla y Ladislao VI el Póstumo, rey de Hungría, citados en el texto. Este autor sugiere, con buena lógica, el año concreto de 1454 como fecha más exacta. Vid. pág. 20 de la introducción por $\mathrm{J}$. Vives y pág. 1 del texto de Tafur. Hemos utilizado la edición realizada por Ediciones «El Albir».

56 RADES, ob. cit. fol. $79 \mathrm{v}$. 
conocido personaje, sobre el cual, a mediados del siglo $x V$ y años antes de su muerte, se habian pronunciado en forma muy laudatoria algunos autores de la época que le conocieron de cerca. Un miembro de su linaje, el poeta y cronista Fernán Pérez de Guzmán, trazó del comendador mayor, cuando éste no era más que un joven, una imagen muy encomiástica, aunque recogiendo en ella su reserva: Fernán Gómez estaba aún en plena juventud y, debido a ello, solamente podía alabarse su «buen principiar». El cronista, al aceptar así la teoría tópica en la historiografía griega - que él debía de conocer bien-según la cual es la muerte la que sentencia de manera definitiva la actuación de un hombre, recordaba, seguramente, aunque sin nombrarlas, aquellas viejas historias de Creso y de Polícrates que narra Heródoto. Y para nosotros, que conocemos el fin trágico del comendador, parece como si en esas palabras hubiera una premonición ${ }^{57}$.

Pero sobre el comendador mayor hay otros dos testimonios posteriores que datan de la época en la que él había asumido ya ese cargo dentro de la Orden de Calatrava. Son los ofrecidos por Pedro Tafur, autor de un famoso libro de viajes escrito a mediados del siglo $x \mathrm{~V}$, y por el cronista Alfonso de Palencia ${ }^{58}$. Uno y otro eran, al parecer, íntimos amigos de Fernán Gómez de Guzmán; uno y otro le dedicaron sendas obras, en cuyo prólogo ensalzan las virtudes de un personaje al que tradicionalmente se suele tener por muy abyecto ${ }^{59}$. Aunque encontramos en esos autores alabanzas a la formación cultural de Fernán Gómez de Guzmán,

57 Del poeta es regla rectal que el que bien comenzól a la mitad ya llegól de obra buena e perfecta:/ tanto me agrada e delecta/ vuestro buen principiar,/ que vos presumo loar/ antes de la edad provecta./Bien me menbra que el loor/ en la fin se ha de cantar e de justo o pecador/ la muerte ha de sentenciar; e si el bien comenzar/ algunas vezes causó, $/$ pero quien no comenzól jamás non pudo acabar./ Non me engaña la afficción/ nin el deudo turba el seso/ nin va torcido el peso/ de mi poca discreción:/ vuestra dulce condición/ e discreta jouentud/ muestran en vos la virtud/ de vuestra generación./ Non sé joya más preciadal quel buen mozo uirtuoso/ nin bestia más enconada/ quel viejo malo e uicioso; porquel tiempo es peligroso/ tanto de la nueva edad,/ quel mozo usar de honestadf es acto marauilloso. F. PÉREZ DE GUZMÁN: Loores de los claros varones de España, en "Cancionero castallano del siglo Xv", preparado por Fouché Delbosc en Nueva Biblioteca de Autores Españoles, vol. XIX, I, pág. 706.

58 Vid. nota 55.

59 Para Tafur, Fernán Gómez es «noble, culto, instruído y de buen juicio... juzgando con discreción y buena fe acerca de los hombres y de las cosas"; le asigna también "gentil espiritu", "verdadera nobleza" entre los "cabesçeras e governadores de muchos". TAFUR, ob. y p. cit. en nota 55. Palencia, además de dedicarle su Tratado de la perfección del triunfo militar, hace frecuentes alusiones de tipo laudatorio en su obra cronística. Vid., por ejemplo, Décadas, Lib. XXVI, Cap. IV. 
generalmente suelen insistir siempre en las virtudes militares del comendador, las cuales heredó, sin duda, de su padre.

El problema más árduo es el de demostrar si heredó también las aspiraciones al maestrazo de Calatrava. Dada su pertenencia a la Orden desde fecha relativamente temprana, Fernán Gómez de Guzmán tuvo que vivir de manera intensa las vicisitudes que llevaron a su progenitor a enfrentarse con Pedro Girón; y no es aventurado suponer que entre sus proyectos estuviera el de conseguir el maestrazgo, antes o después, movido tanto por la propia conciencia de su valía personal como por el deseo de satisfacer una vieja aspiración familiar frustrada en el caso de su padre, pero realizada plenamente con anterioridad por otros miembros de su linaje. Al fin y al cabo, los Guzmán podían considerar a Girón como un advenedizo en la Orden de Calatrava, a pesar de haber tenido en el maestrazgo de ella, en el siglo XIV, un precedente ilustre de su mismo nombre. De todas formas, no conocemos pruebas concluyentes a través de las cuales se pueda demostrar que entre Pedro Girón y su nuevo comendador mayor existió una rivalidad parecida a la que había enfrentado a aquél con el padre de este último. Sí es conocida, en cambio, la «falta de aprecio» - así la llama el cronista Palencia- que Fernán Gómez sintió, más adelante, hacia Rodrigo Girón, hijo de Pedro Girón y sucesor suyo en el maestrazgo ${ }^{60}$. Por otra parte y al margen de ciertos indicios a los que nos referiremos con posterioridad, la situación imperante en Castilla y el poder acumulado por Pedro Girón y por su hermano el marqués de Villena hacian totalmente inviable cualquier proyecto de cambio en la cúpula de la orden militar.

\section{DE OSUNA A FUENTEOVEJUNA ¿UN NUEVO AGRAVIO?}

Al igual que otros maestres anteriores (entre los cuales los ejemplos de Lorenzo Suárez de Figueroa, en la Orden de Santiago, o Gutierre de Sotomayor, en la de Alcántara, eran dos casos a imitar o, incluso, a superar), Pedro Girón aspiraba a conseguir bienes de fortuna al margen de la Orden con los que crear un mayorazgo para poder transmitirlo a alguno de sus hijos; todo lo cual era compatible con su intento de legar

60 Palencia: Crônica de Enrique $N$, ed. BAE, II, pág. 285. 
a otro de ellos el maestrazgo de Calatrava ${ }^{61}$. $Y$ a lo largo de la realización de esos dos proyectos terminó por chocar con los intereses de su comendador mayor.

Es en torno a 1458 cuando se consolida el proceso para la constitución de un señorío nobiliario, en favor del maestre, aunque ese proceso se había iniciado tiempo atrás ${ }^{62}$. Del año citado data la adquisición de la villa de Gelves y el intento, que no tuvo éxito, de conseguir la de Fregenal ${ }^{63}$. Como consecuencia de ello surge en su favor un bloque de señorios andaluces al serle concedida por Enrique IV la villa de Morón, seguida luego por las de Fuenteovejuna y Belmez ${ }^{64}$. Estas dos últimas habían formado parte de los señoríos del maeste de Alcántara, Gutierre de Sotomayor, a partir de 1449 y 1450; pero don Gutierre encontró dificultades para conservarlas en su poder, tuvo que hacer frente, en 1453, a una sublevación en Fuenteovejuna, promovida desde Córdoba, y no pudo conseguir que su sucesor en esos señoríos ejerciera su dominio sobre las dos villas citadas a causa del tremendo esfuerzo que Córdoba realizó para recuperarlas ${ }^{65}$. Un enconado pleito por cuestión de términos, existente en Belmez y otros lugares vecinos (que aún estaba sin sustanciarse en 1455) puso de manifiesto lo difícil que era conseguir un señorío viable sobre esta villa y la de Fuenteovejuna, que habían dado claras muestras de resultar muy conflictivas ${ }^{66}$.

6† Sobre los señoríos nobiliarios conseguidos por Lorenzo Suárez de Figueroa, vid. F. Mazo: El Condado de Feria (1394-1505), Badajoz 1980. En relación con los señoríos de Gutierre de Sotomayor, vid. E. CABRERA: El condado de Belalcázar (1444-1518). Córdoba 1977. Sobre la transmisión del maestrazgo a Rodrigo Téllez Girón, vid. EnRIQuez: Crónica de Enrique $N$, pág. ?

62 Merced de Peñafiel y San Felices de Gallegos. AHN, Osuna, Leg. 2-19.

${ }^{63}$ LADERO: Andalucía en el siglo XV, p. 34.

${ }_{64}$ AHN, Osuna, Leg. 35-1. Vid. a este respecto también RADES, ob. cit., fol. 74.

65 El 6 de febrero de 1453, el concejo de Córdoba dictaba unas ordenanzas para el cobro de determinadas tasas con el fin de allegar recursos con que financiar la empresa de recuperación de Fuenteovejuna y Belmez, además de las de Gahete e Hinojosa. En el texto de esas ordenanzas se dice que «nuestra villa de Fuenteovejuna, acatando la lealtad e fidelidad que deua al dicho sennor rey e a esta dicha çibdad (de Córdoba), cuyos son, echaron e apartaron de sy la dicha alienaçión e ocupaçión que dellos el dicho maestre tenía fecha, e son tornados a la corona real... e nos enbyaron suplicar e pedir por merçed... que les nos mandásemos enbyar socorro de gente..." Archivo Municipal de Córdoba, Tumbo de Privilegios fol. 53 v..

${ }_{66}$ Sobre el tema de la primera señorialización de Fuenteovejuna y Belmez, vid. E. CABRERA: El condado de Belalcázar, págs. 130-144, 159-162 y 243-244. También, “Usurpación de tierras y abusos señoriales en la Sierra cordobesa durante los siglos XIV y XV", Actas del I Congreso de Historia de Andalucia. Andalucia Medieval, II, págs. 57 y siguientes. 
El ejemplo era demasiado claro y estaba lo bastante cercano en el tiempo como para dejar de tomar buena nota de él. Es más, contamos con un testimonio insólito que prueba hasta qué punto se preveian problemas de parte de los naturales de las dos villas señorializadas y, sobre todo, de Córdoba. El domingo 25 de enero de 1461, un día después de la toma de posesión de Fuenteovejuna por Fernando de la Cueva, en nombre de Pedro Girón, el propio Enrique IV, hallándose presente en esa villa, instaba personalmente a sus vecinos para que acatasen la merced hecha al maestre "aunque los de Córdova ni de otra parte alguna... dixesen lo contrario" ${ }^{67}$. Era tan ostensible la dificultad de hacerse con Fuenteovejuna y Belmez que en la mente de Pedro Girón se abrió camino la idea de intentar una permuta de las villas cordobesas con el fin no sólo de olbiar dificultades fácilmente imaginables, sino también de obtener el máximo provecho de los señoríos recibidos. Gelves, Morón, Fuenteovejuna y Belmez formaban un señorío demasiado disperso; las dos últimas villas citadas eran una fuente potencial de problemas; también lo era la cercanía de Morón a la villa de Osuna, sede tradicional de la encomienda mayor, cuyo nuevo titular, Fernán Gómez de Guzmán, no era un vecino demasiado fiable ${ }^{68}$. A todas esas consideraciones debió de unirse, como elemento básico, el reciente interés que el maestre de Calatrava sentía por Andalucía, que se centró en el territorio comprendido entre la frontera granadina - siendo plazas de su atención Olvera y, posteriormente, Archidona - y las ciudades de Carmona y Sevilla, sobre las cuales ejerció una poderosa influencia.

Se abrió camino de ese modo la idea de establecer un acuerdo con la Orden de Calatrava encaminado a ceder a ésta las villas de Fuenteovejuna y Belmez, a cambio de Osuna y La Puebla de Cazalla. El primer paso en ese sentido se dio ya en 1461 mediante información al papa sobre el cambio propuesto a fin de solicitar su aprobación ${ }^{69}$. En marzo de 1462 , el pontífice concedía permiso para efectuar la permuta ${ }^{70}$. Sin embargo, hasta 1464 no decidió la orden llevar a efecto el cambio propuesto y con anterioridad a esta última fecha, una comisión de la misma

${ }^{67}$ AMC, Secc. If, Caja 71, doc. 57. Inserto en el pleito entre Fuenteovejuna y Córdoba, Apartado n. ${ }^{\circ} 14$.

68 Osuna había quedado constituida como sede de la encomienda mayor desde el reinado de Alfonso X. Vid. Bullarium Ordinis Militae de Calatrava, pág. 124, doc. de 29 de diciembre de 1264.

69 El 17 de agosto de 1461 el papa mandaba hacer una información al respecto. Vid. O'Callaghan, ob. cit., pág. 34.

70 lbidem. 
estudió el caso con detenimiento trasladándose a Fuenteovejuna y a Belmez a fin de conocer sobre el terreno el interés que estos dos pueblos cordobeses podian tener para la orden de Calatrava ${ }^{71}$. Un capítulo general celebrado en Porcuna en el mes de marzo de 1464 aprobó la permuta ${ }^{72}$. Las actas que han quedado de la reunión capitular parecen no dejar lugar a la duda en cuanto a la utilidad que supuso para la Orden el cambio realizado ${ }^{73}$. Entre los que expresaron claramente su opinión está el propio comendador mayor Fernán Gómez de Guzmán, que fue el primero en emitirla. Para él, "considerando la gran poblaçión que en la dicha villa de Fuenteouejuna ay..., a la dicha horden convenía e en ello reçibia notorio e evidente provecho en fazer el dicho troque". Añadía «que este hera su voto e paresçer en Dios e en su conçiençia syn otra afeçion ni amor ni ynterese que en ello le fuese ${ }^{74}$. A pesar de esa última frase ¿era sincera su opinión? Rades y Andrada, al comentar en su Chrónica la reunión capitular de Porcuna entiende, basándose tal vez en testimonios que no han llegado a nosotros, que el maestre obtuvo más o menos por la fuerza el consentimiento de muchos comendadores, a pesar de que "era muy notorio el agravio y enorme el daño que de

71 Actuaron como diputados de la Orden para dilucidar el asunto Frey Alvar Pérez de Medina, comendador de Auñón, Frey Pedro de Oviedo, subclavero, Frey Alfonso de Cáceres, comendador de las casas de Toledo, y Frey Altonso de Almagro, prior de las casas de Sevilla. Una copia del proceso en Archivo Catedralicio de Sevilla, Leg. 14, Osuna, 32-6-20.

72 Ibidem.

73 Hay numerosos testimonios de los comendadores de la orden donde se insiste, con razón o sin ella, en esa idea. Los argumentos que alegan son casi siempre los mismos: era mayor el número de habitantes de Fuenteovejuna (985) y Belmez (123) que el de Osuna (519) y Cazalla (estaba despoblada); resulta útil y conveniente la compensación económica que anualmente daría el rey a la orden para igualar el montante de las rentas de Osuna y Cazalla que, pese a todo, eran superiores a las de Fuenteovejuna y Belmez; las dos villas cordobesas atravesaban un momento de prosperidad, al contrario de lo que sucedía a las dos sevillanas, las cuales, además, se hallaban muy alejadas de los restantes territorios de la Orden y - la observación merece reseñarse demasiado próximas a la frontera granadina. Se insiste igualmente en el interés particular que tenía la fortaleza de Belmez. Uno de esos testimonios puede ser elocuente y resumir a los demás. Dice que «se devía consyderar que la dicha villa de Fuentevejuna hera una villa tan grande e de tanta poblaçión en que biben e moran vasallos e vezinos muchos e ricos e de grandes cabdales e faziendas e en la dicha villa de Belmez una fortaleza tan grande e prinçipal e tan bien reparada... que es mucho mejor e más fuerte que la que es en la dicha villa de Osuna, mayormente acatando commo las dichas villas de Fuenteovejuna e Belmes con el dicho heredamiento de los Cañuelos que el dicho señor rey da se junta con otros lugares e rentas que tiene la dicha horden e se fortaleçen los unos lugares e heredamientos con los otros que se fayen más propincos; e la dicha villa de Osuna está apartada e no tanto llegada a la dicha orden e bienes della, por lo qual non podría ni puede ser asy administrada nin governada nin defendida segund e como devía».

${ }^{74}$ Archivo Catedralicio de Sevilla, doc. cit., fol. 27 y v. 
esto recibía la Orden, por ser mayores y mejores los pueblos que daba que los que le daban» ${ }^{75}$.

Suponiendo que la apreciación de Rades se correspondiera con la realidad, no cabe duda de que Fernán Gómez de Guzmán recibía un evidente agravio con el cambio de Osuna y la Puebla de Cazalla por Fuenteovejuna y Belmez. Con ello se producía, además, una situación nueva en el esquema administrativo de la Orden, pues la primera de las dos villas sevillanas era sede de la encomienda mayor desde hacía justamente doscientos años, ya que fue erigida como tal, por Alfonso $X$, en $1264^{76}$. Por otra parte, logrado el cambio, el comendador mayor accedía, cuando menos, a dos villas tremendamente conflictivas, dada la oposición que siempre habían manifestado, apoyadas por Córdoba, hacia el dominio señorial. Resulta difícil no ver en todo ello una jugada verdaderamente maestra por parte de Pedro Girón hacia el hijo y sucesor de su antiguo enemigo.

De todas formas, suponiendo que la permuta efectuada no hubiera sido motivo de enfrentamientos entre el maestre y el comendador mayor, sí había de serlo, en cambio, la forma abusiva en que Pedro Girón organizó esos cambios: el maestre entregó las dos villas a Fernán Gómez de Guzmán, pero retuvo el castillo de Belmez, con lo cual le dejaba sin fuerza alguna en su encomienda, porque la otra villa, Fuenteovejuna, no tenía propiamente un castillo que mereciera ser llamado con ese nombre ${ }^{77}$. Puede decirse que Fernán Gómez de Guzmán estaba a merced de cualquier maniobra que Córdoba quisiera organizar para recuperar sus antiguos lugares.

Si es que alguna vez se había apagado el odio por los viejos enfrentamientos, ese hecho debió de reavivarlos entre Pedro Girón y el hijo de su antiguo rival. Incluso la propia actitud del maestre de retener la poderosa fortaleza de Belmez era algo más que una humillación al comendador mayor de la Orden: era, quizá por encima de otra cosa, la expresión más palpable de su temor a que pudiera reproducirse en Belmez una situación parecida a la que Juan Ramírez de Guzmán había dado lugar en Zorita veinte años antes. Aunque todo ello quizá fuese tan sólo una muestra de prepotencia, por parte del maestre, para hundir definitiva-

75 Rades, ob. cit. fol. $74 \mathrm{~V}$.

6 Vid. nota 66.

77 Palencla, ob. cit., vol. II, págs. 285-286 
mente al último protagonista de una historia que creía ya resuelta definitivamente a su favor. La gravedad de los acontecimientos que se suscitaron a partir de 1464 en todo el reino explica, no obstante, la actitud de Girón lo mismo que hacen presumible un reverdecer del odio entre los dos personajes y, quizá al calor de él, una renovación de las aspiraciones al maestrazgo de Calatrava en el seno de la familia Guzmán, representada, en este caso, por el hijo de Juan Ramírez y sucesor suyo en el cargo de comendador mayor. Sin embargo, tal aspiración de Fernán Gómez, aunque muy probable, es muy difícil de demostrar; y tanto o más difícil aún habría sido llevarla a práctica, en caso de haber existido, teniendo en cuenta el poder que alcanzaba en ese momento el maestre tanto por sí mismo como por el apoyo de su todopoderoso hermano el marqués de Villena. Por eso no parece haber testimonios de una actitud rebelde de Fernán Gómez de Guzmán en vida del maestre. Pero a la muerte inesperada de éste, en 1466, y cuando el maestrazgo fue legado al hijo de Girón, Rodrigo Téllez, que no tenía entonces más que ocho años, la situación cambió sustancialmente, pues la posición del maestreniño quedó mucho más débil que lo había sido la de su padre. Rades afirma que el Papa tuvo que conferirle el maestrazgo en encomienda porque no podía dárselo en título ${ }^{78}$. Y sólo el enorme poder del marqués de Villena, que actuó como tutor, pudo mantener la situación ${ }^{79}$. Palencia habla de la intromisión de Pacheco en la Orden de Calatrava y de lo que ello le pesaba al comendador mayor ${ }^{80}$. Afirma, además, que el marqués procuró romper con el comendador mayor para arrebatarle también la villa de Fuenteovejuna ${ }^{81}$. $Y$ de su relato cabe deducir una situación muy tensa entre el comendador mayor y su joven maestre, pues el primero se mantuvo "constantemente hostil, desde la muerte del maestre Pacheco, a don Rodrigo Girón» ${ }^{82}$.

La muerte del marqués de Villena fue la señal que el comendador mayor esperaba para tomar la iniciativa y fue entonces cuando puso sitio al castillo de Belmez ${ }^{83}$. El propio Palencia nos informa de que la esperanza de conquistar la fortaleza aumento cuando se produjo la muerte de Enrique IV, pues Fernán Gómez de Guzmán había servido a Fernando e

\footnotetext{
Rades, ob. cit. fol. $78 y^{\circ} \mathrm{B}$.

PALENCIA, ob. cit. II, págs. 285-286.

Ibidem, pág. 285 B.

Ibidem, pág. 286 A.

lbidem, pág. 285 B.

lbidem, pág. 286 A.
} 
Isabel ya incluso durante el reinado de su antecesor ${ }^{84}$. Es este un tema del máximo interés, pues desde que la "comedia" de Lope popularizó el tema de Fuenteovejuna y su comendador, se ha propagado la idea errónea -introducida por el Fénix de los Ingenios- de que Fernán Gómez de Guzmán sirvió la causa del rey portugués ${ }^{85}$. Sin embargo, en la guerra civil que muy pronto se produjo, el joven maestre de Calatrava adoptó el partido de Alfonso de Portugal, mientras, por el contrario, tanto el comendador mayor como el clavero de Calatrava, García de Padilla, actuaron a favor de Fernando e Isabel. La colaboración entre el comendador mayor y el clavero es significativa tanto en su mutua alianza como en su oposición al joven maestre a que hicieran la guerra en compañía de otros destacados miembros del partido aragonés ${ }^{86}$. ¿Es aventurado imaginar que Fernán Gómez de Guzmán encontró en la nueva situación, que acababa de crearse, una coyuntura favorable para intentar conseguir el maestrazgo que su padre no había podido obtener unos decenios antes? Su alianza con el clavero, tercera autoridad de la Orden, ¿no es un síntoma evidente de que en el seno de ella había surgido con toda nitidez un grave enfrentamiento al calor de la guerra civil?

Casi no hay testimonios al respecto. Pero Alfonso de Palencia, que conocía muy de cerca a Fernán Gómez de Guzmán, afirma que «lo mismo don Rodrígo (Téllez) Girón que don Alfonso de Aguilar y cuanto veían con malos ojos la actividad del valiente caudillo y temblaban ante sus planes, cuya ejecución facilitaban sus riquezas, andaban buscando medio de deshacerse del Comendador ${ }^{87}$. Esa confesión de Palencia alusiva a los planes de Fernán Gómez de Guzmán es más que signifi-

84 Ibidem. Nos consta que en 12 de marzo de 1476 Fernán Gómez se hacía vasallo del rey Fernando, según se deduce de un albalá ortorgado por éste por el que le recibía como tal (Real Academia de la Historia, Colección Salazar, M-22, fol. 158. La fecha citada por Salazar, 1496, es errónea. De todas formas, desde mucho tiempo antes está bien documentada la participación del comendador mayor de Calatrava entre el grupo de nobles que luchaban a favor de la causa de Fernando e isabel. Vid. E. Cabrera: El condado de Belalcázar pág. 454, doc. n. ${ }^{\circ}$ 36. También ABAD DE RuTE: Historia de la Casa de Córdoba, Córdoba 1954, pág. 277. PALENCIA nos informa, incluso, de que Fernán Gómez era «estimadísimo con justo título por el rey por sus muchos servicios a la Corona, como esforzado adalid y tenaz perseguidor de los aliados del potugués" (pág. $285 \mathrm{~A}$ ).

85 Vid. sobre este tema, E. CABRERA: «La sublevación de Fuenteovejuna de 1476. Revisión del problema”. En Andalucia Medieval. Nuevos Estudios. Córdoba 1979, págs. 147-174.

86 Palencia, ob. cit., pág. $286 \mathrm{~A}$.

87 lbidem, pág. 285. 
cativa, lo mismo que lo es la muerte del personaje en Fuenteovejuna, el 22 de abril de 1476, muerte que el cronista atribuye a una conjura de sus enemigos ${ }^{88}$. Con ella termina una lucha por el maestrazgo de Calatrava que había durado una generación.

88 lbidem, pág. 286. 